\title{
Utility of neonatal early-onset sepsis calculator in risk- based group B Streptococcus screening approach
}

Myo-Jing Kim, MD

Department of Pediatrics, Dong-A University College of Medicine, Busan, Korea

\begin{abstract}
Key message
Evaluation of the risk factors for early-onset sepsis (EOS) is important to optimal prevention and treatment.

- The EOS calculator is still valid as part of the risk-based group B Streptococcus (GBS) screening approach.

The risk factor assessment using the EOS calculator is worth use before the introduction of universal GBS screening.
\end{abstract}

Group B Streptococcus (GBS) infection in neonates is acquired in utero through a clinically symptomatic or asymptomatic intraamniotic infection, during rupture of the membranes, or during passage through the vagina colonized with GBS. Most earlyonset sepsis (EOS) cases in neonates are secondary to vertical transmission from maternal vaginal and rectal GBS colonization. EOS by GBS is a leading cause of severe infection in the neonate. ${ }^{1)}$ Therefore, evaluation of the risk factors for EOS is important to its optimal prevention and treatment. ${ }^{2)}$ GBS colonization rates reportedly vary geographically at $18.6 \%-26.5 \%$ in the United States ${ }^{1)}$ and $6 \%-32 \%$ in Europe. ${ }^{3)}$ Screening for the intrapartum administration of antibiotic prophylaxis (IAP) has been performed using universal or risk-based GBS screening. The universal GBS screening approach involves routine antepartum GBS vaginal and rectal cultures of all pregnant women; subsequently, all who are colonized receive IAP. In the risk-based GBS screening approach, women receive IAP according to the presence of risk factors. ${ }^{4}$ Universal GBS screening is practiced in the United States and Canada and in European countries with some modifications, whereas risk-based GBS screening is recommended in the United Kingdom, Denmark, and the Netherlands. ${ }^{4,5)}$ Owing to these preventive strategies, the incidence of EOS by GBS has markedly declined over the 15 years from 1.7 cases per 1,000 live births to 0.34-0.37 cases per 1,000 live births in the United States. ${ }^{1)}$

In South Korea, research is lacking on which approach is more effective, while maternal GBS colonization data are insufficient due to low GBS prevalence rates. ${ }^{6,7)}$ However, recent studies reported an increase in maternal GBS colonization from $0.3 \%$ $5.9 \%$ before 2010 to $2.0 \%-11.6 \%$ in recent years ${ }^{8-16}$ ) (Table 1). A Korean nationwide survey reported that GBS accounted for $0.5 \%$ of all cases of neonatal sepsis and was increasing after
$2000 .^{7}$ In this regard, there is growing concern regarding the introduction of the universal GBS screening approach in South Korea instead of the risk-based GBS screening approach. $\left.{ }^{6}\right)$ Risk-based GBS screening may miss preventable GBS cases in countries with a high incidence. However, universal GBS screening is cost-ineffective because the incidence of GBS neonatal sepsis in South Korea is low, and it has several disadvantages including false-negative screening results, risk of antibioticinduced anaphylaxis, and changes in GBS serotypes resulting in antibiotic resistance. ${ }^{4,5)}$

Therefore, the study conducted by Achten et al. ${ }^{17)}$ published in the current issue has great implications for South Korea, as it reveals that use of the EOS calculator is still valid with the riskbased GBS screening approach.

This study evaluates the impact of GBS status when applying the EOS calculator in risk-based GBS screening, as it calculates the EOS risk and recommends management at birth and after the recalculation of a definitive GBS status. The EOS calculator is used worldwide to improve the accuracy of empirical antibiotic administration for assessing multivariate risk based on 5 maternal

Table 1. Maternal GBS colonization data of South Korea since 2000

\begin{tabular}{llcc}
\hline Study & \multicolumn{1}{c}{ Period } & $\begin{array}{c}\text { No. of } \\
\text { participants }\end{array}$ & $\begin{array}{c}\text { Colonization } \\
\text { rate }\end{array}$ \\
\hline Choi et al. ${ }^{8)}(2002)$ & $2000-2001$ & 204 & $2.0 \%$ \\
Kim et al. ${ }^{9)}(2004)$ & $2002-2003$ & 58 & $3.4 \%$ \\
Kim et al. ${ }^{10)}(2006)$ & 2005 & 273 & $4.8 \%$ \\
Uh et al. ${ }^{11)}(2009)$ & $2008-2009$ & 234 & $11.5 \%$ \\
Oh et al. ${ }^{12)}(2009)$ & $2005-2006$ & 667 & $6.3 \%$ \\
Hong et al. ${ }^{13) *(2010)}$ & $2006-2007$ (SNUBH) & 1,216 & $10.0 \%$ \\
& 2007 (BWMS) & 2,828 & $4.0 \%$ \\
Lee et al. $^{14)}(2010)$ & $2006-2008$ & 2,624 & $8.0 \%$ \\
Kim et al. ${ }^{15)}(2011)$ & $2006-2008$ & 2,644 & $8.3 \%$ \\
Yook et al. ${ }^{16)}(2013)$ & $2006-2011$ & 5,095 & $8.0 \%$ \\
Kim et al. ${ }^{7)}(2018)$ & $2015-2016$ & 1,014 & $11.6 \%$ \\
Hong et al. ${ }^{6)}(2019)$ & $2016-2017$ & 795 & $7.9 \%$ \\
\hline
\end{tabular}

GBS, group B Streptococcus.

This study was performed at 2 different institutions (SNUBH, Seoul National University Bundang Hospital; and BWMS, Bombit Women's Medical Service).

Corresponding author: Myo-Jing Kim, MD. Department of Pediatrics, Dong-A University College of Medicine, 32 Daesingongwon-ro, Seo-gu, Busan 49201, Korea 凶E-mail: myojing@dau.ac.kr, https://orcid.org/0000-0002-8296-3382

Received: 30 March, 2020, Revised: 28 April, 2020, Accepted: 15 May, 2020

This is an open-access article distributed under the terms of the Creative Commons Attribution Non-Commercial License (http://creativecommons.org/licenses/bync/4.0/) which permits unrestricted non-commercial use, distribution, and reproduction in any medium, provided the original work is properly cited.

Copyright (c) 2020 by The Korean Pediatric Society 
risk factors and the patient's clinical condition to estimate EOS. The management recommendation consists of 3 steps. ${ }^{18)}$ According to Dutch guidelines, risk-based GBS screening is performed in cases of prematurity, intrapartum fever $\left(\geq 38^{\circ} \mathrm{C}\right)$, rupture of the membranes $\geq 18$ hours, previous delivery of an infant affected by GBS disease, and IAP administered in cases of GBS bacteriuria. ${ }^{19)}$ Nevertheless, maternal GBS status is an important risk factor on EOS the calculator; in risk-based GBS screenings, it is possible that maternal GBS colonization information may not manifest until birth. Therefore, it is important to evaluate whether the EOS calculator is compatible with risk-based GBS screening.

In this study, the EOS calculator recommendation remained unchanged for $97 \%$ of neonates at risk for EOS after recalculation of the EOS risk using the definitive GBS results, which were not yet available at birth. "Unknown" cases of GBS status comprise $86.4 \%$ of births and $21.6 \%$ of definitive GBS results. Based on results of this study, the risk-based GBS screening method has only a marginal impact on EOS calculator management recommendations in neonates. In other words, use of the risk-based GBS screening method did not result in the withholding of antibiotic treatment from infants at risk of EOS.

In conclusion, use of the EOS calculator is still valid with the risk-based GBS screening approach. This finding has great implications for South Korea, where controversy regarding the need for universal GBS screening exists. Risk factor assessments using an EOS calculator are worth applying before the introduction of universal GBS screening. Further studies are needed to confirm EOS calculator utility in South Korea clinical practice.

\section{Conflicts of interest}

The author declares no conflicts of interest relevant to this article.

See the article "Risk-based maternal group B Streptococcus screening strategy is compatible with neonatal early-onset sepsis calculator implementation" via https://doi.org/10.3345/ cep.2020.00094.

\section{References}

1. Verani JR, McGee L, Schrag SJ; Division of Bacterial Diseases, National Center for Immunization and Respiratory Diseases, Centers for Disease Control and Prevention (CDC). Prevention of perinatal group B streptococcal disease--revised guidelines from CDC, 2010. MMWR Recomm Rep 2010;59:1-36.

2. Spotswood N, Grace E, Keir AK. A quantitative, risk-based approach to the management of neonatal early-onset sepsis. Acta Paediatr 2018; 107:1474-5.

3. Barcaite E, Bartusevicius A, Tameliene R, Kliucinskas M, Maleckiene L, Nadisauskiene R. Prevalence of maternal group B streptococcal colonisation in European countries. Acta Obstet Gynecol Scand 2008;87:26071.
4. Homer CS, Scarf V, Catling C, Davis D. Culture-based versus riskbased screening for the prevention of group $\mathrm{B}$ streptococcal disease in newborns: a review of national guidelines. Women Birth 2014;27:46-51.

5. Kurz E, Davis D. Routine culture-based screening versus risk-based management for the prevention of early-onset group B Streptococcus disease in the neonate: a systematic review. JBI Database System Rev Implement Rep 2015;13:206-46.

6. Hong JY, Kim SH, Kim SM, Yee CA, Choi SJ, Oh SY, et al. Evaluation of the early onset neonatal sepsis according to two antenatal group B Streptococcus screening methods: risk-based versus universal screening. Perinatology 2019;30:200-7.

7. Kim DH, Min BJ, Jung EJ, Jeong DH, Lee KB, Sung MS, et al. Prevalence of group B Streptococcus colonization in pregnant women in a tertiary care center in Korea. Obstet Gyneco Sci 2018;61:575-83.

8. Choi KU, Koh SK, Lee JY, Park JH, Hwang SO, Lee BI, et al. Clinical significance of group B streptococcal infection in pregnant women. Korean J Obstet Gynecol 2002;45:811-5.

9. Kim TH, Park SE, Kim KH. A study of group B streptococcal infection in pregnant women, by LIM broth media. Korean J Pediatr 2004;47:10725.

10. Kim MW, Jang HO, Chang DY, Cho JR, Kim YA, Choi HM, et al. Group B streptococcal colonization rate in Korean pregnant women. Korean J Obstet Gynecol 2006;49:337-44.

11. Uh Y, Choi SJ, Jang IH, Lee KS, Cho HM, Kwon O, et al. Colonization rate, serotypes, and distributions of macrolide-lincosamide-streptogramin B resistant types of group B streptococci in pregnant women. Korean J Clin Microbiol 2009;12:174-9.

12. Oh CE, Jang HO, Kim NH, Lee J, Choi EH, Lee HJ. Molecular serotyping of group B Streptococcus isolated from the pregnant women by polymerase chain reaction and sequence analysis. Korean J Pediatr Infect Dis 2009;16:47-53.

13. Hong JS, Choi CW, Park KU, Kim SN, Lee HJ, Lee HR, et al. Genital group B Streptococcus carrier rate and serotype distribution in Korean pregnant women: implications for group B streptococcal disease in Korean neonates. J Perinat Med 2010;38:373-7.

14. Lee BK, Song YR, Kim MY, Yang JH, Shin JH, Seo YS, et al. Epidemiology of group B Streptococcus in Korean pregnant women. Epidemiol Infect 2010;138:292-8.

15. Kim EJ, Oh KY, Kim MY, Seo YS, Shin JH, Song YR, et al. Risk factors for group B Streptococcus colonization among pregnant women in Korea. Epidemiol Health 2011;33:e2011010.

16. Yook JH, Kim MY, Kim EJ, Yang JH, Ryu HM, Oh KY, et al. Risk factors associated with group B Streptococcus resistant to clindamycin and ery. thromycin in pregnant Korean women. Infect Chemother 2013;45:299307.

17. Achten NB, Dorigo-Zetsma JW, van Rossum AMC, Oostenbrink R, Plötz FB. Risk-based maternal group B Streptococcus screening strategy is compatible with neonatal early-onset sepsis calculator implementation. Clin Exp Pediatr 2020;63:406-10.

18. Achten NB, Dorigo-Zetsma JW, van der Linden PD, van Brakel M, Plötz FB. Sepsis calculator implementation reduces empiric antibiotics for suspected early-onset sepsis. Eur J Pediatr 2018;177:741-6.

19. Di Renzo GC, Melin P, Berardi A, Blennow M, Carbonell-Estrany X, Donzelli GP, et al. Intrapartum GBS screening and antibiotic prophylaxis: A European consensus conference. J Matern Neonatal Med 2015;28: 766-82.

How to cite this article: Kim MJ. Utility of neonatal earlyonset sepsis calculator in risk-based group B Streptococcus screening approach. Clin Exp Pediatr 2020;63:393-4. https:// doi.org/10.3345/cep.2020.00500 